\title{
Experimental Investigation on Switching Characteristics of High-Current Insulated Gate Bipolar Transistors at Low Currents
}

\author{
Anirudh Guha, Aniket Datta, C. Rangesh Babu, G. Narayanan \\ Department of Electrical Engineering \\ Indian Institute of Science, Bangalore - 560012 INDIA \\ Email: aguha@ee.iisc.ernet.in; aniketdatta@ee.iisc.ernet.in; rangeshbabu2037@gmail.com; gnar@ee.iisc.ernet.in
}

\begin{abstract}
Insulated gate bipolar transistors (IGBTs) are used in high-power voltage-source converters rated up to hundreds of kilowatts or even a few megawatts. Knowledge of device switching characteristics is required for reliable design and operation of the converters. Switching characteristics are studied widely at high current levels, and corresponding data are available in datasheets. But the devices in a converter also switch low currents close to the zero crossings of the line currents. Further, the switching behaviour under these conditions could significantly influence the output waveform quality including zero crossover distortion. Hence, the switching characteristics of high-current IGBTs (300$A$ and 75-A IGBT modules) at low load current magnitudes are investigated experimentally in this paper. The collector current, gate-emitter voltage and collector-emitter voltage are measured at various low values of current (less than $10 \%$ of the device rated current). A specially designed in-house constructed coaxial current transformer (CCT) is used for device current measurement without increasing the loop inductance in the power circuit. Experimental results show that the device voltage rise time increases significantly during turn-off transitions at low currents.
\end{abstract}

\section{INTRODUCTION}

Insulated gate bipolar junction transistors (IGBTs) are widely used in ac to dc and dc to ac power conversion [1]-[3]. The capacities of IGBT-based voltage source converters (VSC) extend upto 100's of kilowatts and even a few megawatts [3], [4]. For a capacity of a few hundred kilowatts and dc voltage ranging between $600 \mathrm{~V}$ and $800 \mathrm{~V}$, the device current is of the order of 100s of amperes [4]. The power dissipation in an IGBT is quite high when it switches high current. Hence, the switching characteristics of IGBTs at high currents have been studied extensively [5], [6].

But, the line current in a voltage source converter is sinusoidal. Hence, the IGBTs also switch low currents close to the current zero-crossings. The switching characteristics at low currents could significantly influence the quality of output waveform including distortion of line current at zero crossings. However, the switching transition data are usually not available

This work is funded by the Department of Heavy Industry, Government of India, under a project titled " Off-line and Real-time Simulators for Electric Vehicle/ Hybrid Electric Vehicle Systems”. in the datasheets for low values of current [7], [8]. Hence this paper studies the switching characteristics of $1200 \mathrm{~V} / 300 \mathrm{~A}$ and $1200 \mathrm{~V} / 75 \mathrm{~A}$ IGBT modules at low currents (less than $10 \%$ of the rated current).

Measurement of switching characteristics require measurement of the device current. The IGBTs and dc capacitors are connected using a sandwich bus-bar arrangement to keep the parasitic inductance low [9], [10] and prevent possible device failure due to over-voltage. It is not possible to insert a current probe in a sandwich bus-bar arrangement. Hence, a coaxial current transformer (CCT) is used here to measure the device current [11], [12].

The experimental setup is detailed in section II. The measured switching characteristics of the 300-A IGBT module are presented in section III. The experimental procedure is repeated on a 75-A IGBT module in section IV. The rise time of the device voltage is shown to increase significantly at low currents for both 300-A and 75-A devices. The implication of this is discussed briefly in section $\mathrm{V}$.

\section{DESCRIPTION OF EXPERIMENTAL SETUP}

A 300-A, 1200-V, half-bridge IGBT module (SKM300GB124D) can be used as one leg of a $100 \mathrm{KVA}$ three-phase VSC. The module is configured as a chopper as shown in Fig. 1 to study the switching characteristics of this 300-A IGBT. The device terminals and capacitor terminals are connected with a sandwich bus-bar, as illustrated in Fig.2, to keep the parasitic inductance low. To measure the device current without increasing the stray inductance in the power circuit, a coaxial current transformer (CCT) is employed [11]. This is mounted between the emitter terminal of the bottom device and the negative terminal of the dc capacitor as shown in Fig. 1.

The emitter current enters the outer limb of the CCT primary through a bus-bar plate. This current leaves the CCT through the inner (central) limb of the primary as illustrated in Fig.2. The current flows into the negative terminal of the dc capacitor through another bus-bar plate. A toroidal core is placed in the annular region between the inner and outer 


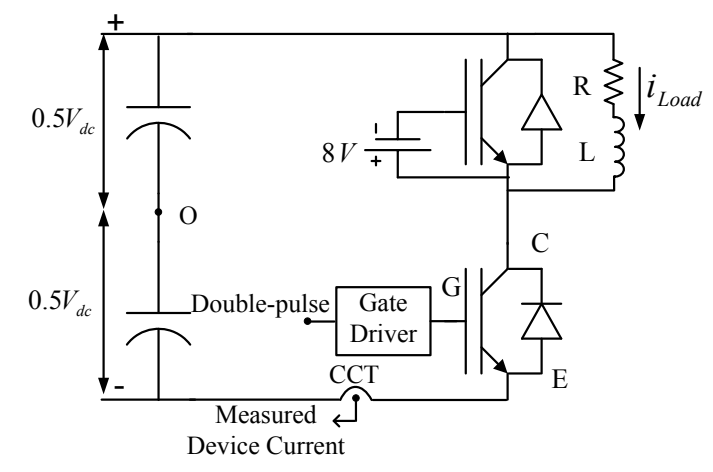

Fig. 1. Test circuit configuration for obtaining device switching characteristics.

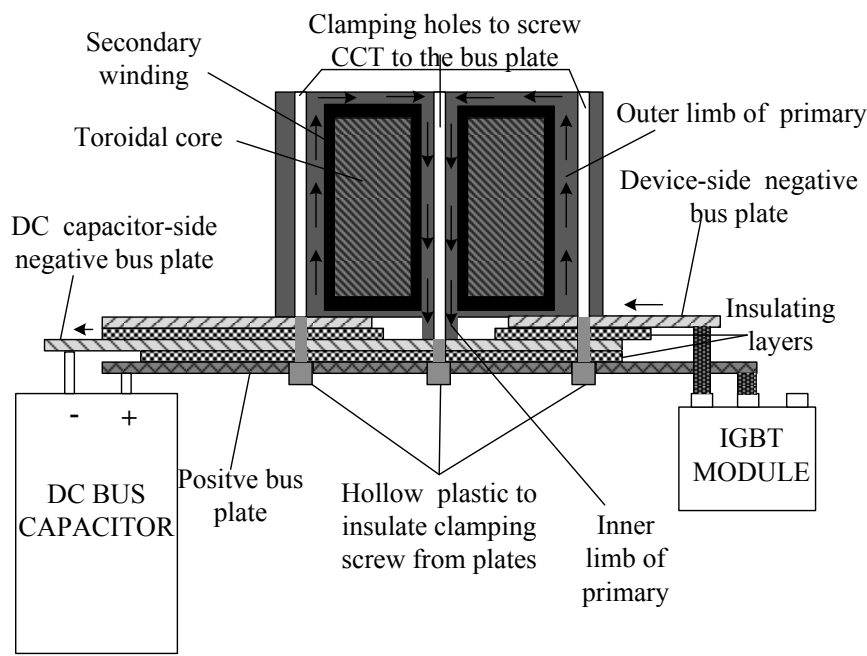

Fig. 2. Schematic representation of the coaxial current transformer and sandwich bus-bar structure [11]. (Figure dimensions are not to scale; Thickness of plates and insulation are exaggerated for clarity.)

limbs of the primary. The secondary of the CCT is a thin copper strip wound around a toroidal core. The secondary current is measured by means of a commercial current probe. A photograph of the experimental set-up is given in Fig. 3.

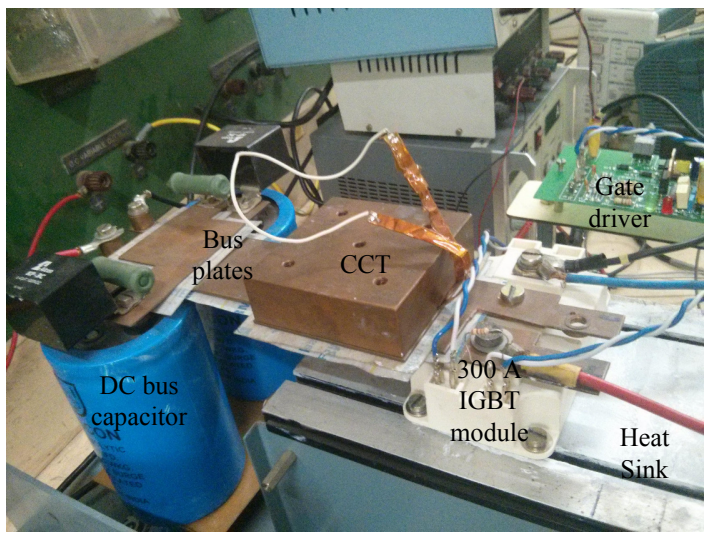

Fig. 3. Photograph of the experimental setup.

The tests are performed at a dc bus voltage of $600 \mathrm{~V}$. The load current is switched between the top diode and bottom IGBT (see Fig. 1), which is driven by a gate driver [13], through a gate resistance $\left(R_{g}\right)$ of $5.6 \Omega$. The on-state and off-state gate voltages are $+15 \mathrm{~V}$ and $-8 \mathrm{~V}$, respectively. A gate voltage of $-8 \mathrm{~V}$ keeps the top IGBT turned-off, ensuring that it does not turn-on due to any oscillations initiated when the bottom IGBT is switched.

A double-pulse chopper test is performed to obtain the device switching characteristics [5], [12], [14]. A monoshot double pulse gating signal and the corresponding current build up in the RL load are illustrated in Fig. 4. The pulse width $t_{1}$ is selected to build up the load current (and device current) to the desired level, before it is turned-off. A large load inductance and a small notch width $\left(t_{2}\right)$ are selected to keep the load current nearly constant during the notch. The device is turnedon at the end of the notch period, when a short pulse of width $t_{3}$ is applied. The turn-off transient is captured at the end of the interval $t_{1}$; the turn-on transient at the desired current level is captured at the end of the interval $t_{2}$. The measured switching

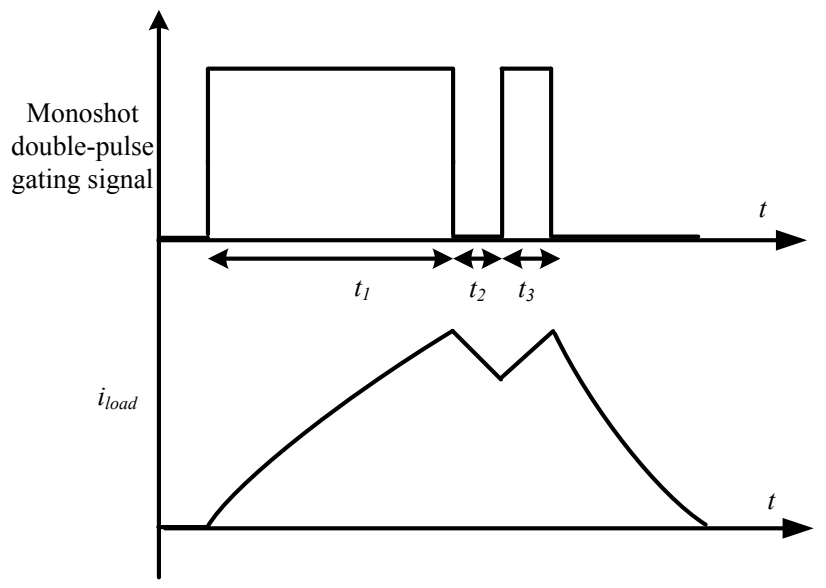

Fig. 4. Monoshot double pulse gate voltage and corresponding load current

characteristics of the 300-A IGBT module are presented in the following section.

\section{EXPERIMENTAL RESULTS ON 300A/1200V IGBT}

The turn-off switching characteristics of the 300-A IGBT module (SKM300GB124D), obtained at a load current level of 1A, are shown in Fig. 5(a). The measured collector current $i_{c}$, the collector-emitter voltage $v_{C E}$, the gate-emitter voltage $v_{G E}$ and gate current $i_{g}$ are shown by traces $1,2,3$ and 4 , respectively. The turn-on switching characteristics at the same current of 1A are presented in Fig. 5(b), with the traces defined similar to Fig. 5(a). The switching characteristics are measured at various currents ranging between $1 \mathrm{~A}(0.33 \%$ of $300 \mathrm{~A})$ and $30 \mathrm{~A}(10 \%$ of $300 \mathrm{~A})$. The switching characteristics at a current level of 30A are presented in Fig. 6. The characteristics at a higher load current of 150A are also shown in Fig. 7 to indicate the typical switching characteristics of an IGBT.

The peak turn-on currents observed in Fig. 5 to Fig. 7 are higher than the load currents being switched; this is attributed 


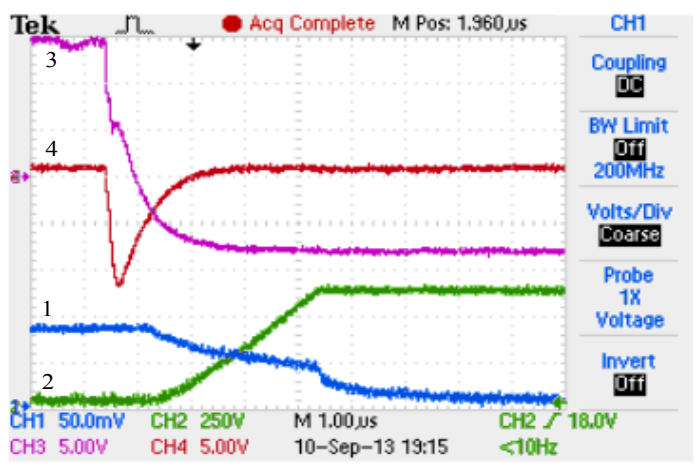

(a)

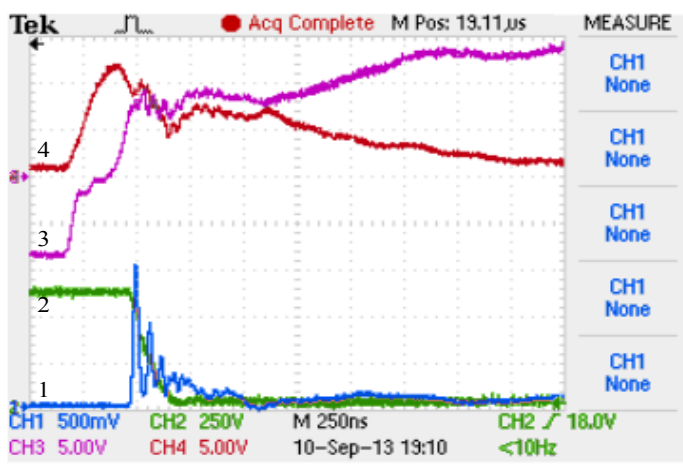

(b)

Fig. 5. Measured switching characteristics of SKM300GB124D at 1A current level with $R_{g}=5.6 \Omega$ (a) turn-off characteristics, Trace 1: collector current $i_{c}(0.643 \mathrm{~A} / \mathrm{div})$, time scale: $1 \mu \mathrm{s} / \mathrm{div}$ (b) turn-on characteristics, Trace 1: collector current $i_{c}(6.43 \mathrm{~A} / \mathrm{div})$, Trace 2 : collector emitter voltage $v_{C E}(250$ V/div), Trace 3: gate emitter voltage $v_{G E}(5 \mathrm{~V} / \mathrm{div})$, Trace 4: gate current $i_{g}$ (0.893 A/div), time scale: 250 ns/div.

to the diode reverse recovery current. The ratio of the peak turn-on current to the load current increases as the load current magnitude decreases as observed from Fig. 8.

The turn-on delay time $\left(t_{d o n}\right)$, the rise time $\left(t_{r}\right)$, the turn-off delay time $\left(t_{d o f f}\right)$ and the fall time $\left(t_{f}\right)$ are measured as per [14], [15] at different values of load current. These are shown in Fig. 9. It is seen from Fig. 9 that the turn-on delay time and rise time are very small; these remain nearly constant at low load current magnitudes. However, the turn-off delay and fall times are much higher as shown by Fig. 9.

The typical turn-off current at higher current levels, depicted at $150 \mathrm{~A}$ in Fig. 7(a), is characterised by a fast falling current ( $\approx 1300 \mathrm{~A} / \mu \mathrm{s}$ ), followed by a tail current falling with a low slope. The tail current is insignificant in comparison to the fast falling current portion of the transient.

But the turn-off characteristics at 30A in Fig. 6(a) is significantly different from that at 150A in Fig. 7(a). The collector current initially falls at a slow rate during the interval when the collector-emitter voltage rises. After the collector voltage has increased to the dc bus voltage, the current falls quickly at around $240 \mathrm{~A} / \mu \mathrm{s}$. This is followed by a slow falling tail. In contrast to the characteristics at $150 \mathrm{~A}$, the initial current fall and tail current are significant in comparison to the fast falling current. Also, at a very low current level of $1 \mathrm{~A}$, the

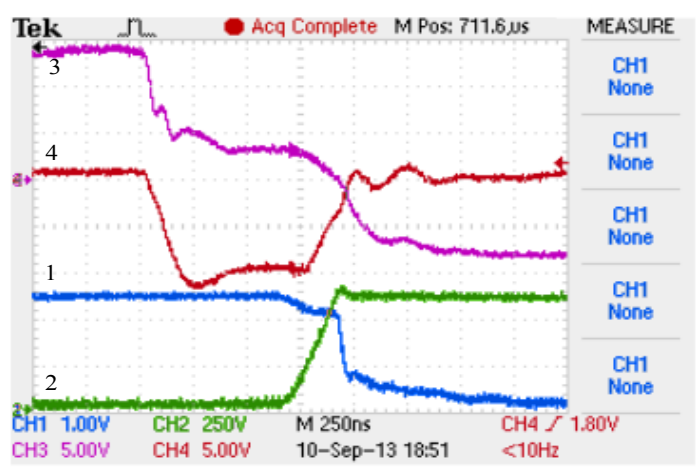

(a)

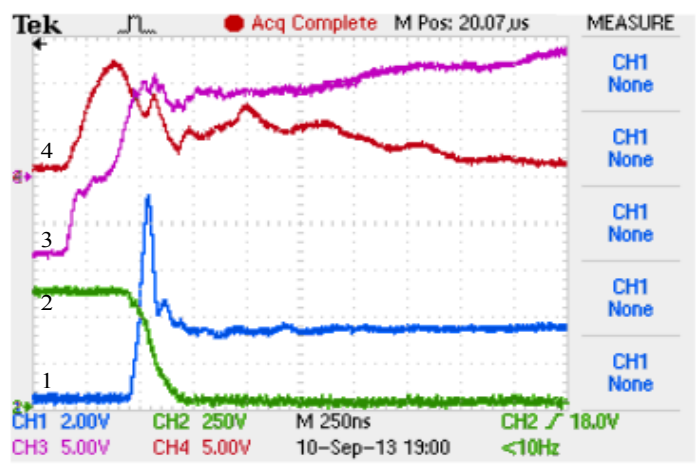

(b)

Fig. 6. Measured switching characteristics of SKM300GB124D at 30A current level with $R_{g}=5.6 \Omega$ (a) turn-off characteristics, Trace 1: collector current $i_{c}(12.85 \mathrm{~A} / \mathrm{div})$ (b) turn-on characteristics, Trace 1: collector current $i_{c}(25.7 \mathrm{~A} / \mathrm{div})$, Trace 2: collector emitter voltage $v_{C E}(250 \mathrm{~V} / \mathrm{div})$, Trace 3: gate emitter voltage $v_{G E}(5 \mathrm{~V} /$ div $)$, Trace 4: gate current $i_{g}(0.893 \mathrm{~A} / \mathrm{div})$, time scale: $250 \mathrm{~ns} /$ div.

current shown in Fig. 5(a) is characterised by an initial slow falling current $(\approx 0.2 \mathrm{~A} / \mu \mathrm{s})$, and then, a very short interval of fast falling current, followed by a significant tail current finally. Thus, while switching off at low current levels, the initial current fall duration (when the device voltage rises) and the tail current duration are significant. In fact, these two intervals are more dominant than the interval during which current falls steeply. Fall time is considered as the interval between the instants the collector current falls from $90 \%$ to $10 \%$ of the load current. The measured fall times at low current magnitudes increase to the order of a few microseconds as seen from Fig. 9.

Further, when switching low currents, there is a significant delay between the transition of the applied gate voltage and that of the device voltage as seen from Fig. 5 and Fig. 6. When the device is turned-on, the gate-emitter voltage rises gradually from $-8 \mathrm{~V}\left(V_{G G-}\right)$ to $15 \mathrm{~V}\left(V_{G G+}\right)$; the total gate voltage swing is $23 \mathrm{~V}$. The turn-on voltage delay $t_{d o n v}$ is measured starting at the instant the gate-emitter voltage $\left(v_{G E}\right)$ has increased by $10 \%$ of the total gate voltage swing from $V_{G G-}$. The turn-on delay is measured till the instant $v_{C E}$ has dropped to $90 \%$ of the dc bus or blocking voltage. Similarly, during device turnoff, the turn-off voltage delay is measured from the time $v_{G E}$ has decreased by $10 \%$ of the total gate voltage swing from 


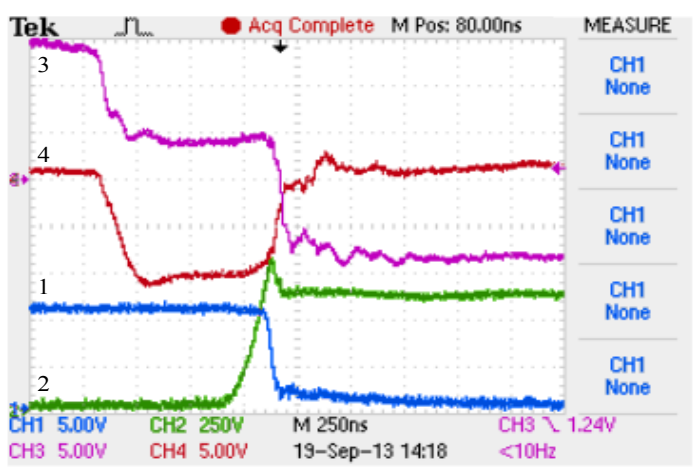

(a)

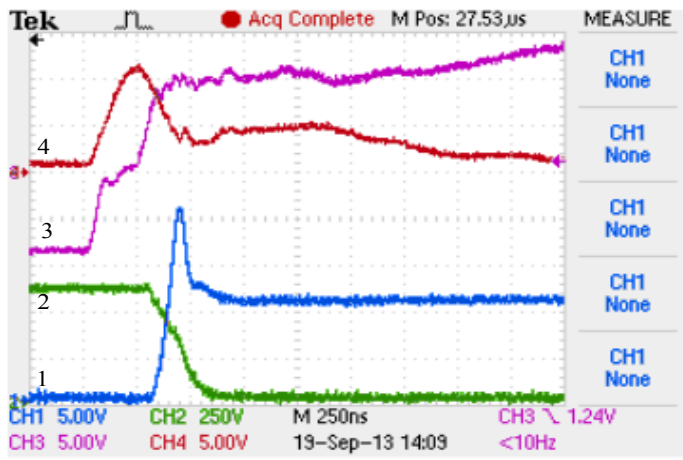

(b)

Fig. 7. Measured switching characteristics of SKM300GB124D at 150A current level with $R_{g}=5.6 \Omega$ (a) turn-off characteristics (b) turn-on characteristics, Trace 1: collector current $i_{c}(64.25 \mathrm{~A} / \mathrm{div})$, Trace 2: collector emitter voltage $v_{C E}\left(250 \mathrm{~V} /\right.$ div), Trace 3: gate emitter voltage $v_{G E}(5 \mathrm{~V} /$ div $)$, Trace 4: gate current $i_{g}(0.893 \mathrm{~A} / \mathrm{div})$, time scale: $250 \mathrm{~ns} / \mathrm{div}$.

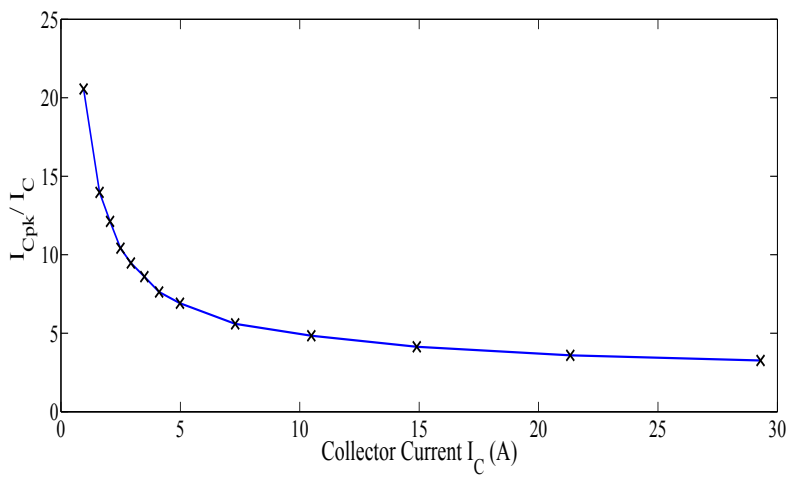

Fig. 8. Variation of the peak turn-on current of SKM300GB124D with the load current, for $R_{g}=5.6 \Omega$.

$V_{G G+}$. The turn-off delay $t_{d o f f v}$ is measured till the instant $v_{C E}$ has risen to $10 \%$ of the dc bus voltage. The fall time $t_{f v}$ is defined as the time it takes $v_{C E}$ to decrease from $90 \%$ to $10 \%$ of the dc bus voltage, during turn-on. Similarly, the voltage rise time $t_{r v}$ is defined as the interval in which $v_{C E}$ rises from $10 \%$ to $90 \%$ of the dc bus voltage, during turn-off. Thus, a device voltage $\left(v_{C E}\right)$ transition can be characterised by a delay time and a rise/fall time.

The measured voltage delay and transition times at different collector current levels are plotted in Fig. 10. It is observed that

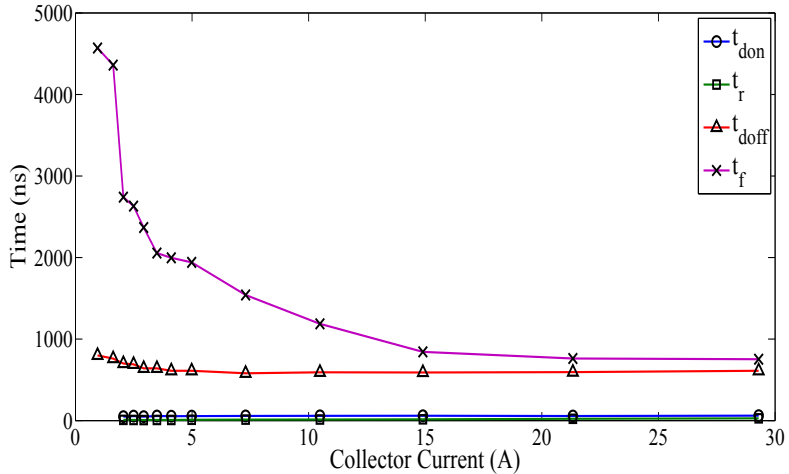

Fig. 9. Variation of the device switching times of SKM300GB124D with the collector current, for $R_{g}=5.6 \Omega$.

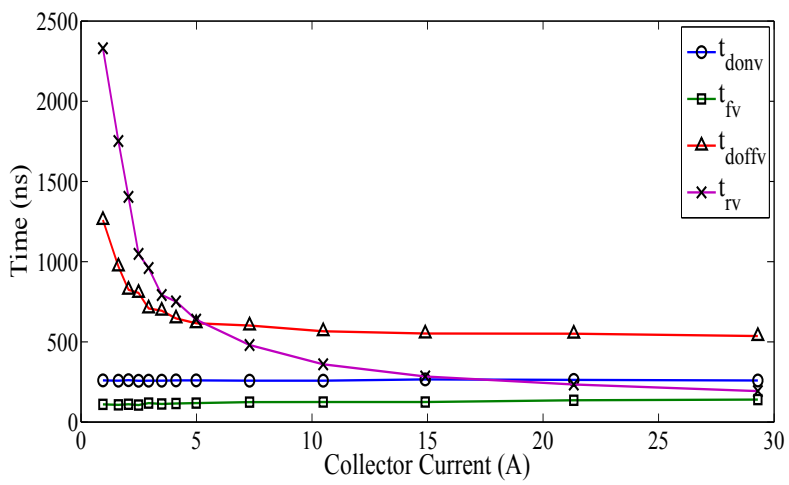

Fig. 10. Variation of voltage delay and collector-emitter voltage transition times of SKM300GB124D with the collector current, for $R_{g}=5.6 \Omega$.

there is a significant increase in the voltage rise time during turn-off, when switching very low currents such as $1 \mathrm{~A}$.

The observations regarding the switching behaviour of IGBT at low current levels are verified on a 75-A IGBT module in the following section.

\section{EXPERIMENTAL RESULTS ON 75A/1200V IGBT}

Experiments similar to those in section III are performed on a 75-A, 1200-V IGBT module (SKM75GB123D) using a $22 \Omega$ gate resistance. The turn-off and turn-on switching characteristics at 0.5A are shown in Fig. 11(a) and Fig. 11(b), respectively. The switching characteristics at $7.5 \mathrm{~A}$ current level are depicted in Fig. 12. The traces are defined in a similar fashion as in section III.

The ratio of the peak turn-on current to the collector current is observed to increase as the current being switched decreases as indicated by Fig. 13. The variation of the device turn-on and turn-off times with the collector current being switched is depicted in Fig. 14. The variation of the voltage transition times with the collector current is presented in Fig. 15. As earlier, the turn-off voltage delay and voltage rise time are longer at very low current magnitudes. Thus, the deviations observed in the switching characteristics at low currents from the typical switching characteristics, are similar for both the 75-A device and 300-A IGBT module. 


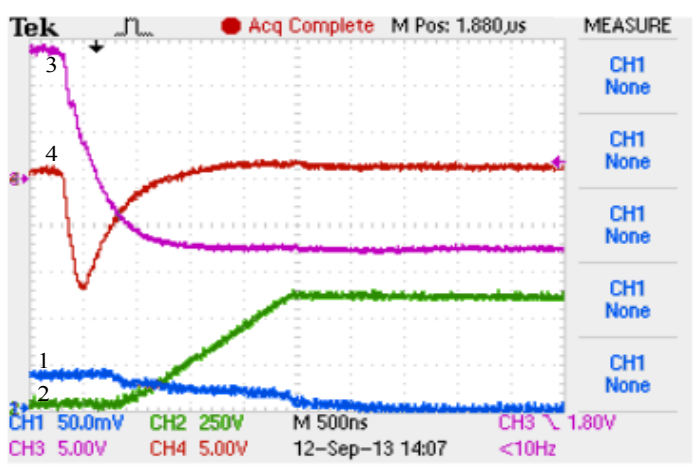

(a)

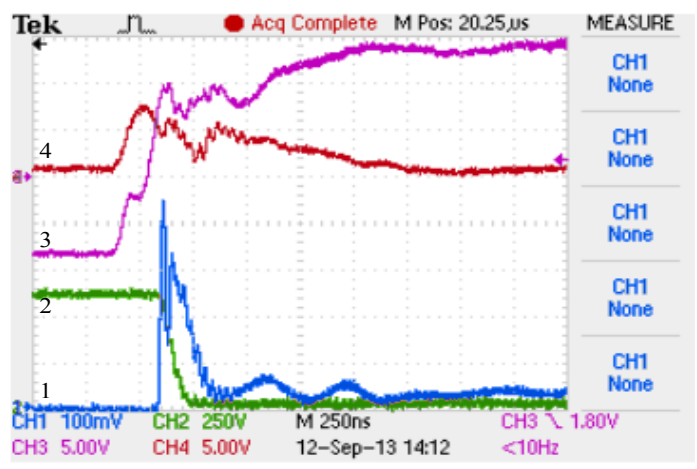

(b)

Fig. 11. Measured switching characteristics of SKM75GB123D at 0.5A current level with $R_{g}=22 \Omega$ (a) turn-off characteristics, Trace 1: collector current $i_{c}(0.643 \mathrm{~A} / \mathrm{div})$, time scale: $500 \mathrm{~ns} / \mathrm{div}$ (b) turn-on characteristics, Trace 1: collector current $i_{c}(1.285 \mathrm{~A} / \mathrm{div})$, Trace 2: collector emitter voltage $v_{C E}(250 \mathrm{~V} / \mathrm{div})$, Trace 3: gate emitter voltage $v_{G E}(5 \mathrm{~V} / \mathrm{div})$, Trace 4: gate current $i_{g}(0.227 \mathrm{~A} /$ div $)$, time scale: $250 \mathrm{~ns} /$ div.

The impact of the increased switching delay and collector emitter voltage transition times on the inverter output voltage is discussed in the following section.

\section{DISCUSSION}

When an inverter leg is switching low currents (around the current zero-crossing), there is a significant delay between the actual edge of the gating signal and device voltage transition. Both the turn-on voltage transition and turn-off voltage transition are delayed by $t_{d o n v}$ and $t_{d o f f v}$ respectively. If $t_{d o n v}$ and $t_{d o f f v}$ are roughly equal, then these result mainly in a propagation delay that adds to the other propagation delays in the system. However, as observed from Fig. 10 and Fig.15, $t_{d o f f v}$ is much longer than $t_{d o n v}$. Hence the effective duty ratio is changed. This change is significant when the output voltage pulse-widths are small. This happens particularly at low modulation indices and/or high switching frequencies.

Further, the device voltage transitions are assumed to have a very high slope. But, as observed from Fig. 10 and Fig.15, the voltage rise time is significantly longer at low current levels and decreases as the current being switched increases. The voltage rise time can be significant in comparison to the pulse-width; hence the output voltage pulse may no longer be rectangular with vertical edges. This causes further deviation

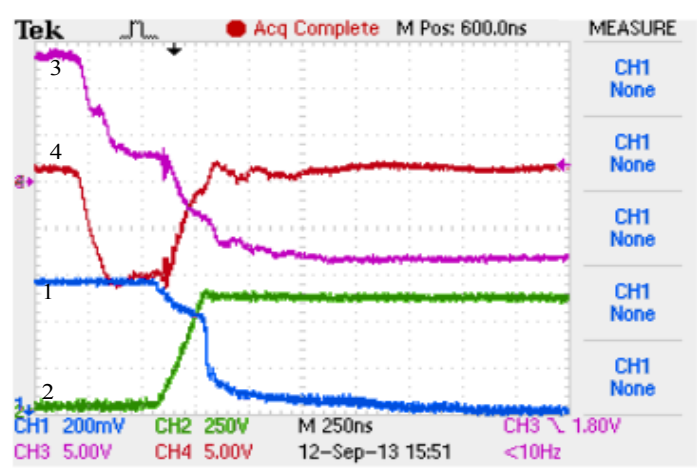

(a)

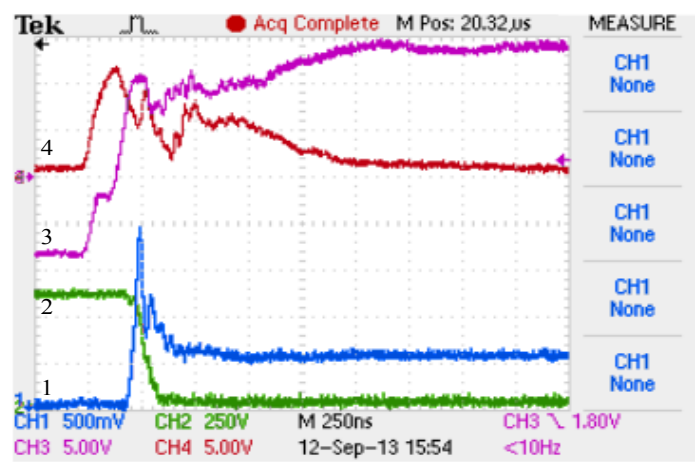

(b)

Fig. 12. Measured switching characteristics of SKM75GB123D at 7.5A current level with $R_{g}=22 \Omega$ (a) turn-off characteristics, Trace 1: collector current $i_{c}(2.57 \mathrm{~A} / \mathrm{div})$ (b) turn-on characteristics, Trace 1: collector current $i_{c}(6.43 \mathrm{~A} / \mathrm{div})$, Trace 2 : collector emitter voltage $v_{C E}(250 \mathrm{~V} / \mathrm{div})$, Trace 3 : gate emitter voltage $v_{G E}(5 \mathrm{~V} / \mathrm{div})$, Trace 4: gate current $i_{g}(0.227 \mathrm{~A} / \mathrm{div})$, time scale: $250 \mathrm{~ns} /$ div.

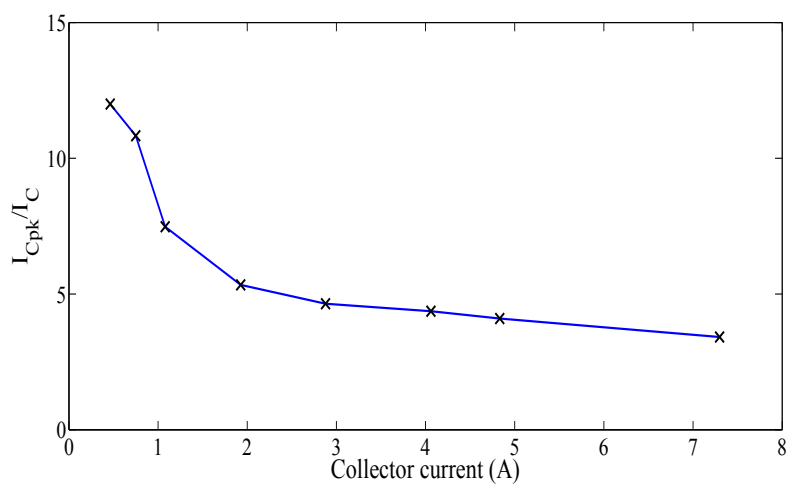

Fig. 13. Variation of the peak turn-on current of SKM75GB123D with the load current, for $R_{g}=22 \Omega$.

from the desired volt-seconds, particularly when the pulse width is low as in the case of low modulation indices.

Further, a delay termed as dead-time is typically introduced between the gating pulses of the complementary switches, to prevent a shoot through fault from occurring during commutation, due to the finite turn-off time of the IGBT. There is a change in the output fundamental voltage and introduction of harmonic distortion resulting on account of dead-time [16], [17]. 


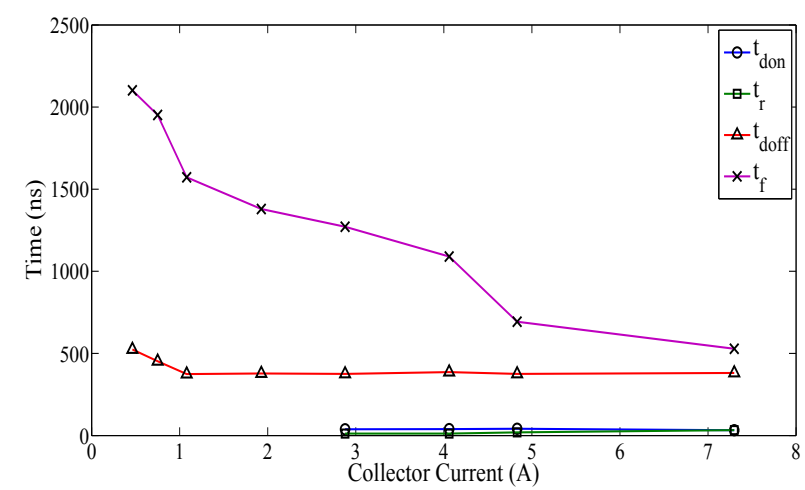

Fig. 14. Variation of the device switching times of SKM75GB123D with the collector current, for $R_{g}=22 \Omega$.

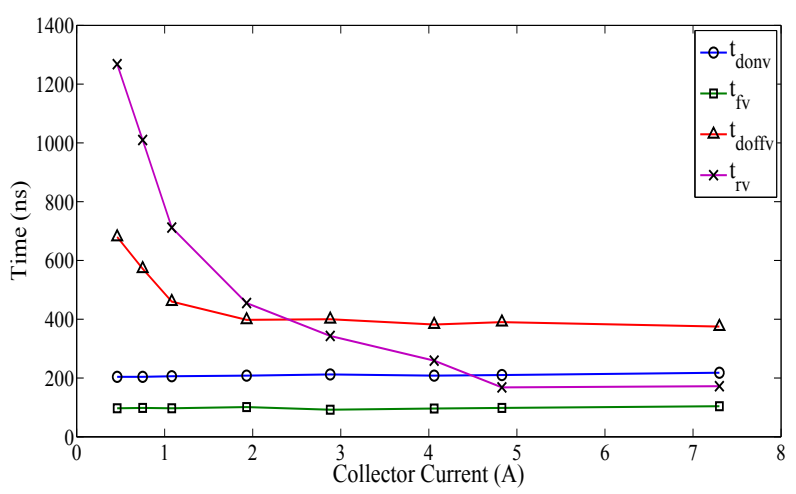

Fig. 15. Variation of voltage delay and collector-emitter voltage transition times of SKM75GB123D with the collector current, with $R_{g}=22 \Omega$.

Dead time compensation schemes [16], [17] mostly assume that the voltage transition times are much shorter than the dead-time interval. While this is valid for higher magnitudes of load current, the voltage rise times are quite significant in the vicinity of the current-zero crossing. Effective dead-time compensation schemes should, hence, consider the variation of the output volt-seconds on account of the switching characteristics of the IGBT at low currents.

\section{CONCLUSION}

The switching characteristics of a 300-A IGBT module are studied experimentally at low current levels. Interesting deviations, particularly during device turn-off, are observed when small load currents are switched. The nature of the variations in the device characteristics of a 300-A module at less than $10 \%$ of the rated current is confirmed by testing a 75-A IGBT module also.

When switching low currents, the ratio of the peak turnon current to the collector current is observed to increase as the load current decreases. The nature of the turn-off current characteristics at low currents is significantly different from the typical switching characteristics at higher currents. From the turn-off characteristics, an initial interval during which current falls slowly (during $V_{C E}$ rise), followed by a fast falling current interval, and finally a tail current interval are typically observed at low currents. The slow falling current intervals dominate and hence the current fall time increases with the decrease in the magnitude of the current switched.

The turn-off voltage delay and the collector-emitter voltage rise times are longer and extend up to a few microseconds at very low current magnitudes. The increased turn-off voltage delay and collector-emitter voltage rise time have a significant impact on the output waveform quality, particularly when the output voltage pulse-width is low.

\section{REFERENCES}

[1] J. M. Carrasco, L. G. Franquelo, J. T. Bialasiewicz, E. Galván, R. P. Guisado, M. A. Prats, J. I. León, and N. Moreno-Alfonso, "Powerelectronic systems for the grid integration of renewable energy sources: A survey," IEEE Trans. Ind. Electron., vol. 53, no. 4, pp. 1002-1016, 2006.

[2] B. Singh, B. N. Singh, A. Chandra, K. Al-Haddad, A. Pandey, and D. P. Kothari, "A review of three-phase improved power quality ac-do converters," IEEE Trans. Ind. Electron., vol. 51, no. 3, pp. 641-660, 2004.

[3] M. Liserre, R. Cárdenas, M. Molinas, and J. Rodriguez, "Overview of multi-MW wind turbines and wind parks," IEEE Trans. Ind. Electron., vol. 58, no. 4, pp. 1081-1095, 2011.

[4] J. S. S. Prasad and G. Narayanan, "Minimum switching loss pulse width modulation for reduced power conversion loss in reactive power compensators," IET Power Electronics, Aug 2013.

[5] F. Blaabjerg, U. Jaeger, and S. Munk-Nielsen, "Power losses in pwmvsi inverter using npt or pt igbt devices," IEEE Trans. Power Electron, vol. 10 , no. 3, pp. 358-367, 1995.

[6] S. C. Das, A. Tiwari, G. Narayanan, and A. K. Kumar, "Experimental investigation on switching characteristics of igbts for traction application," in Proc. IEEE Int Conf. on Power Electron., Drives and Energy Systems, Bangalore, India, Dec 2012, pp. 1-5.

[7] Semikron, SKM300GB124D datasheet. [Online]. Available: http://www.alldatasheet.com

[8] - SKM75GB124D datasheet. [Online]. Available: http://www.alldatasheet.com

[9] Z. Qiu, H. Zhang, and G. Chen, "Study and design of noninductive bus bar for high power switching converter," in Proc. CES/IEEE Power Electron. and Motion Control Conf, vol. 2, Shanghai, China, Aug 2006, pp. 1-4.

[10] L. Yuan, H. Yu, X. Wang, Z. Zhao, and T. Lu, "The large-size lowstray-parameter planar bus bar for high power igbt-based inverters," in Proc. IEEE Int. Conf. Elect. Machines and Syst., Sopporo, Japan, Oct 2012, pp. 1-5.

[11] R. Lyra, B. Filho, V. John, and T. Lipo, "Coaxial current transformer for test and characterization of high-power semiconductor devices under hard and soft switching," IEEE Trans. Ind. Applicat., vol. 36, no. 4, pp. 1181-1188, 2000.

[12] V. Kumar, S. Reddy, and G. Narayanan, "Measurement of igbt switching characteristics and loss using coaxial current transformer," in Proc. IEEE Ind. Applicat. Soc. Annu. Meeting, Delhi, India, Dec 2012, pp. 1-6.

[13] R. Babu, "Study of gate drive circuit and switching charactersistics of high current igbt," Master's thesis, Department of Electrical Engineering, Indian Institue of Science, Bangalore, India, June 2013.

[14] Semikron, Application manual - Power Semiconductors, 2011. [Online]. Available: http://www.semikron.com/skcompub/en/knowledge_base

[15] "International standard, semiconductor devices discrete devices part 9: Insulated-gate bipolar transistors (IGBTs)," IEC Standard 60747-9, Edition 2.0, 2007-09.

[16] Y. Murai, T. Watanabe, and H. Iwasaki, "Waveform distortion and correction circuit for pwm inverters with switching lag-times," IEEE Trans. Ind. Appl., vol. IA-23, no. 5, pp. 881-886, 1987.

[17] M. R. Krishna and G. Narayanan, "A dead-time compensation circuit for voltage source inverters." in Proc. National Power Electron. Conf., Roorkee, India, Jun. 2010. 